\title{
What drives the geeks? Linking computer enthusiasm to achievement goals
}

\author{
Martin Schmettow \\ University of Twente \\ Enschede, The Netherlands \\ m.schmettow@utwente.nl
}

\author{
Matthias Drees \\ University of Twente \\ Enschede, The Netherlands \\ matthiaslukasdrees@gmail.com
}

\begin{abstract}
The personality construct of geekism is introduced as the tendency to act out one's need for cognition in the domain of computing technology. Achievement goal theory is introduced, and we ask, what drives geeks in terms of achievement. In a questionnaire study, it is shown that geekism is related to achievement motivation in imagined situations with technology. Need for cognition showed strong association with self-oriented achievement goals. A newly created scale for computer enthusiasm seems to reflect performance oriented achievement goals.
\end{abstract}

Individual differences, geekism, need-for-cognition, achievement motif, linear mixed-effects models

\section{INTRODUCTION}

People have different stakes in owning and using computers. Presumably, a majority perceive computers as a tool to get the work done, or as a medium for communication and entertainment. Accordingly, most systems are designed to increase productivity, or to serve hedonistic needs, such as entertainment and social identity (Heijden 2004). Under both perspectives designers will try their best to hide the underlying complexity of the system from the user and minimise the cognitive effort necessary to operate the system.

With the emergence of affordable computers appeared the type of the computer enthusiast (Raymond 2008), commonly called the geek. Some authors have examined geeks under the perspective of giftedness (O'Brien 2007), others as suffering from personality disorders (Hunter 2009). In the present paper we take the perspective that computer enthusiasm is a continuous trait (i.e. everybody has it to some extent), as aooposed to a stereotype. For this trait we employ the term geekism, which implies that everybody can be assigned a certain degree of computer enthusiasm.

The present paper explores the motivational structures associated with geekism. A novel questionnaire for assessing computer enthusiasm is used to assess geekism, together with the needfor-cognition scale (Cacioppo et al. 1984). Capitalizing on recent theories on motivation, we explore geekism is associated with achievement goals in technology-related settings.

\subsection{Geekism}

O'Brien studied geeks under the perspective of giftedness. In a multi sample interview study, logical thinking and problem solving emerged as precursors for developing computer technology talent (O'Brien 2007, p.185). Intrinsic motivation was a recurrent theme among the respondents (p.162), and they all stated to put much effort in exploring the computer, with little fear. Several respondents even built their own computers (p.123, 164).

The maker movement perhaps is the currently most salient manifestation of geekism (Diana 2008). While designing one's own computer hardware or software is an extreme case, requiring considerable expertise in addition to passion, the aspect of appropriation is also present in customisation and personalisation of interfaces. Marathe \& Sundar (2011) examine the user experience of customisation, which, as they argue 'are supposed to be ancillary to a primary activity [...] However [...] more and more users spend considerable amount of time customising their interfaces with a great deal of interest and involvement'. While the primary research question was whether the need for control or the (hedonically marked) need for identity drives customisation, they also explored which role it plays that someone is a power user. Interestingly, for power users customisation was more driven by the need of being in control rather than identity, which lead the authors to the conclusion that control is an integral part of agency for [power users]'. 
Schmettow et al. (2013) described geeks as persons driven by an intrinsic interest of delving into (technological) systems with the need to understand their inner working. Emphasising the intellectually challenging nature of computer systems, they argue that the very tendency to enjoy intellectual challenges must be a precondition for geekism. It was shown that persons with a high need for cognition (Cacioppo et al. 1996) were more likely to associate pictures of computers with words that reflect playful interaction, exploration and mastery.

Within the context of this study, geekism is defined as the need to explore, to understand and to tinker with computing devices. Persons with low geekism, use computers merely as tools, or for consuming content, but have no intentions to understand what is going on behind the scenes of crafted services and user interfaces. In contrast, the prototypical geek is interested in computers per se, is not set off by complexity of the system, and would even build or repurpose a computer systems, for example reusing an outdated computer as a home server.

A person with the tendency to avoid intellectually demanding situations can certainly have some superficial, "consumer-ish" positive attitude towards computers, but can hardly be imagined to have strong geekism. Therefore, in our research model, need-for-cognition (Cacioppo et al. 1996) is seen as a necessary component of geekism. In that sense, geeks are persons who like to think and act this out in the domain of technology.

\subsection{Achievement goals}

The achievement motif is a classic psychological construct that captures differences in how strongly individuals are energised to attain goals and strive for ability. A contemporary concept of achievement motivation theory is that ability can be conceived with reference to one selfs performance in the past, or with reference to the ability of others (Ames \& Ames 1984; Dweck 1986; Nicholls 1984). These two dimensions are often labelled as mastery and performance goals. Mastery goals are acted out primarily through developing competence, while performance goals are aimed to demonstrate competence in social comparison, even if this means some superficiality (Elliot et al. 2011). To illustrate this with an example, imagine a student learning for an exam: if the student focuses on developing competence on the subject, instead of (just) getting a good grade on a test, he or she pursues a mastery goal instead of a performance goal. Consequently, performance goals refer to inter-individual standards of comparison, while the mastery goals are associated with intra-individual standards (Elliot et al. 2011).

The achievement goal concept was initially developed to explain students' behaviour in achievement situations. Mastery goals have been found to relate to positive peer relationship, openness to work with classmates, sharing of opinions and tolerance of opposing opinion (Lau et al. 2008). Furthermore, mastery goals are associated with positive learning behaviour, for example adaptive motivational processes (Grant \& Dweck 2003). In general, the association has been made with deep learning strategies, with focus on understanding and elaborating content, in contrast to surface features and memorising facts (Vrugt \& Oort 2008; Lau et al. 2008; Grant \& Dweck 2003). Mastery goals are also linked to persistence and effort, as well as intrinsic motivation (Harackiewicz et al. 2000). In early theories, mastery achievement goals were considered always more beneficial than performance goals (Dweck 1986). However, several researchers also succeeded to show a positive relationship between performance goals and the actual performance (Harackiewicz et al. 2000).

Elliot, Murayama and Pekrun argue that when speaking of achievement goals one must accurately use the point of reference as distinction between the different goals (Elliot et al. 2011). Accordingly, they refer to performance goals as other-oriented goals. Instead of being directed to performance the inter-individual standard moves to the centre of the concept. For mastery goals they propose a further distinction between task-oriented and self-oriented goals. In addition, achievement goals can either be directed at approaching success or avoiding failure.

Despite almost thirty years of research, controversy remains about whether individuals have a stable pattern of achievement goals, or whether this depends on the situation. Whereas Van Yperen (2006) found that $80 \%$ of people have a dominant achievement style across different situations, Elliot \& Thrash (2002) argued that achievement goals are situational.

\subsection{Research Questions}

The present study seeks to explore the association between achievement goals and geekism. Following Van Yperen (2006), it is expected that persons with a geek predisposition act out an achievement motif in technology related situations.

\section{Hypothesis 1: Individuals with a high score on geekism show stronger technology-related achievement motivation as compared to sports.}

Furthermore, the study explores the orientation of technology-related achievement goals. Fiddling with computers is a rather solitary activity compared to sports. It is also harder to think of competitive situations where persons would directly compare in computer expertise. 
Hypothesis 2a: In technology-related situations, persons with strong geekism show overall stronger mastery achievement goals as compared to performance achievement goals.

As shown by Schmettow et al. (2013), person with a geek attitude perceive computers as objects of intellectual challenge, rather than tools to achieve certain tasks. Therefore, it is expected that geekism is associated with self-oriented goals rather than task-oriented.

Hypothesis 2b: Self-oriented achievement goals in the technology domain have the strongest association with geekism, as compared to taskand other-oriented goals.

Finally, in the present study, geekism is assessed by means of the established need-for-cognition scale (NCS), as well as a newly constructed Gex scale, that specifically measures enthusiasm for computers. Accordingly, the current study also aims for validation for the novel scale, as well as explore how it differs to NCS in the context of geekism.

\section{METHODS}

Sample: In total 27 individuals participated in this research. Twelve participants were female, with mean age of $28(\sigma=12)$. Three participants were Dutch and two were English speakers and the rest German. The study was approved by the faculty's ethical commission.

Measures: Two multi-item Likert scales were used to measure geekism: the Gex ${ }^{1}$ questionnaire and the need-for-cognition scale (NCS, Cacioppo et al. 1984). In addition, an implicit picture story exercise $\left(\mathrm{Gimpl}^{2}\right)$ was administered, but these results are not considered, here. Achievement goals were measured by 36 items formulated after Elliot et al. (2011), one half dealing with a sports-related situation, the other with a technology-related situation. All questionnaires were scored on a seven point Likert scale.

The NCS scale consisted of 18 different items revolving around preference for complex thinking and intellectually challenging situations. The NCS has been widely employed in psychological studies (Cacioppo et al. 1996) and has also been introduced as an approximation for geekism (Schmettow et al. 2013).

The achievement goal questionnaire items were constructed after Elliot et al. (2011). To measure technology-related achievement motives, participants were asked to imagine an achievement situation in which they had to learn a complex

\footnotetext{
${ }^{1}$ Gex stands for geekism, explicit

${ }^{2}$ Gimpl stands for geekism, implicit
}

software (SPSS or MS Word) and answer 18 items that represent the different achievement goals (see Table 1). The goals consisted of all combinations goal orientation (task, self and other), and approach and avoidance dimensions. An analogue test was administered using sports-related achievement goals.

Table 1 Example items domains and orientation

\begin{tabular}{|lll|}
\hline $\begin{array}{l}\text { Task } \\
\text { (Mastery) }\end{array}$ & $\begin{array}{l}\text { Technology } \\
\text { know the right way to } \\
\text { use product }\end{array}$ & $\begin{array}{l}\text { Sports } \\
\text { correctly exercise } \\
\text { the sport }\end{array}$ \\
$\begin{array}{l}\text { Self } \\
\text { (Mastery) }\end{array}$ & $\begin{array}{l}\text { improve abilities with } \\
\text { this and comparable } \\
\text { products }\end{array}$ & $\begin{array}{l}\text { improve my } \\
\text { abilities in this } \\
\text { sport }\end{array}$ \\
$\begin{array}{l}\text { Other } \\
\text { (Performance) }\end{array}$ & $\begin{array}{l}\text { work better than } \\
\text { others with the } \\
\text { product }\end{array}$ & win a competition \\
\hline
\end{tabular}

Development of the Gex questionnaire grounded on O'Brien (2007), as well as an own interview study with self-claimed geeks $(n=10)$. From the emerging themes, a set of 32 items were initially derived, covering interest in understanding technology, need for being in control of devices, preference for versatility, motivation to repurpose devices, and privacy concerns. In a yet unpublished evaluation study $(n=90), 17$ items were removed for low consistency or insufficient test-retest stability. The remaining 15 items exhibited outstanding consistency (Cronbach $\alpha=$ $96 \%)$ and excellent test-retest stability $(R=96 \%)$. The resulting scale showed good discriminant validity towards the NCS with a rather low correlation of $R=.36$. The items are printed in the appendix.

Procedure: Participants were invited to a quiet area or room and were asked to fill out the materials. At first an informed consent paper was signed by the participants, informing the participants of their rights, including information of the general purpose of this study. All materials were filled out in one session, which took 45 minutes at most.

Data analysis: Formally, all three constructs are latent variable represented by a number of manifest items. Therefore, the ultimate treatment would be structural equation modelling. However, given the small sample size and the exploratory nature of the research, a multivariate linear mixed-effects model was chosen instead.

Geekism was represented by two scores, Gex and NCS, and entered the regression as predictor for achievement goals. The 36 achievement goal items were taken as the dependent variable. The two aspects, orientation (self, task, other) and domain (technology, sports) were modelled as predictors, 
such that the hypotheses could be tested by interaction effects. To account for the repeated measures, a subject-level intercept random effect was added. Model fitting was done with the MCMCglmm command of the respective package (Hadfield 2010) for the statistical computing environment $R$ (R Development Core Team 2011).

\section{RESULTS}

In $21(1.2 \%)$ cases had an item not been answered. All scores were z-transformed. NCS and Gex scores showed a moderate positive correlation, but hardly beyond chance level $(r=.31, p=.11)$.

Starting with $\mathrm{H} 1$ (geekism associated with technology-related achievement), a regression model (M1, see Table 2) was constructed to contain achievement domain, NCS and Gex as main effects, as well as the interaction effects between geekism predictors (Gex, NCS) on the one hand and domain (technology, sports) on the other hand. In partial confirmation of $\mathrm{H} 1$, a clear association was found between NCS and technology-related achievement goals $\left(\beta_{7}=.30\right)$ as compared to sports-related goals. No such interaction effect was present for the Gex scale $\left(\beta_{6}=.02\right)$ as shown in Figure 1.

Next, another model (M2, see Table 2) was estimated, using only the technology-related responses and by adding interaction effects for orientation of achievement goals. Regarding $\mathrm{H} 2 \mathrm{a}$ (high geekism, strong mastery goals), goal orientation strongly interacts with Gex, but at the opposite of the expected direction: Gex is positively

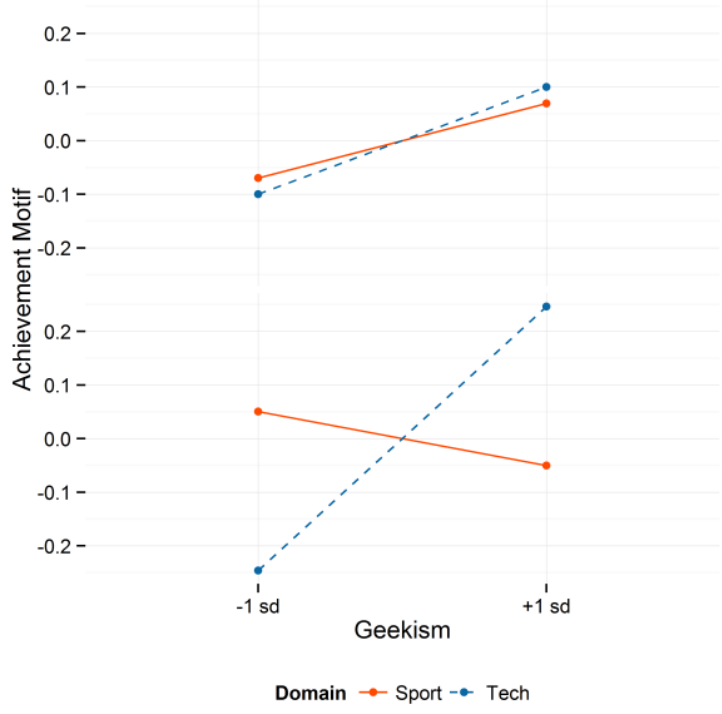

Figure 1 Interaction effects between measures for geekism and achievement domain associated with other-orientation $\left(\beta_{1}=.33\right)$, but both interaction effects are negative (Table 2 ). Speaking in gross effects, the association with task-orientation goals is almost non-existent $\left(\beta_{1}+\beta_{9}=.06\right)$, and negative by tendency for selforientation $\left(\beta_{1}+\beta_{8}=-.10\right)$. Regarding Gex as measure for geekism, $\mathrm{H} 2 \mathrm{~b}$ is not supported.

Next we examine $\mathrm{H} 2 \mathrm{a}$ and $\mathrm{H} 2 \mathrm{~b}$ with respect to NCS. As shown in Figure 2, NCS is positively associated with other-related goals, too, although weaker and less certain than Gex $\left(\beta_{2}=.19\right)$. In support for $\mathrm{H} 2 \mathrm{a}$, a strongly positive and highly certain association between NCS and self-oriented goals was observed $\left(\beta_{2}+\beta_{10}=.45\right)$. However, opposed to $\mathrm{H} 2 \mathrm{~b}$, task orientation has the lowest association with NCS $\left(\beta_{2}+\beta_{11}=.08\right)$.

Two additional observations can be made from Table 2: first, technological situations seem to trigger overall achievement motivation slightly stronger as compared to sports situations (M1, $\left.\beta_{3}=.12\right)$. Second, in technology situations participants rated themselves overall higher on selforiented goals (M2, $\beta_{4}=.21$ ), and even more so on task-oriented goals $\left(\mathrm{M} 2, \beta_{5}=.37\right)$.

\section{DISCUSSION}

Persons with strong need-for-cognition reported overall stronger achievement goals in technologyrelated situations, but less so with sports. This does not seem to be the case for computer enthusiasm, as assessed by the Gex scale. Inasmuch as needfor-cognition is viewed a component of geekism, hypothesis $\mathrm{H} 1$ is supported.

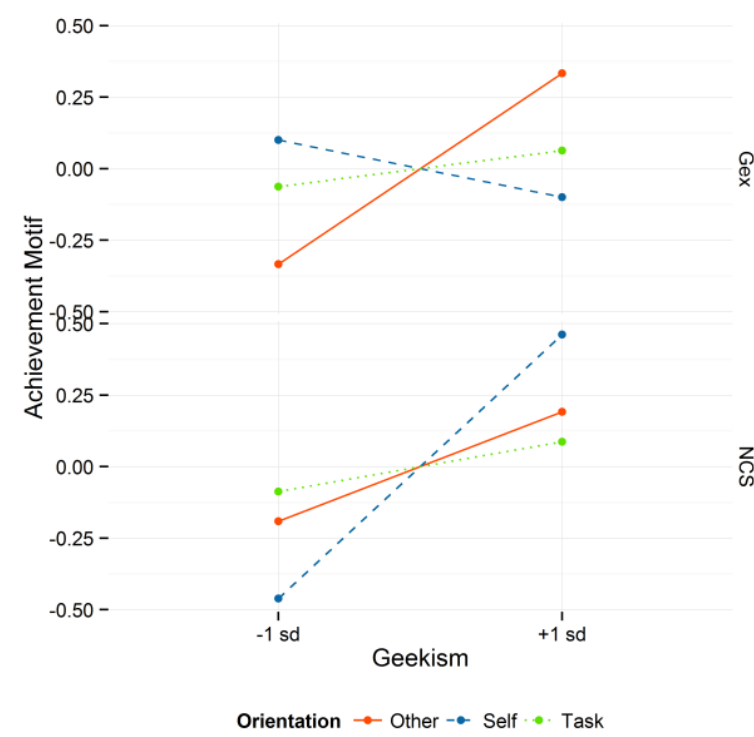

Figure 2 Interaction effects between measures for geekism and achievement orientation 
Table 2 Regression results

\begin{tabular}{lccc}
\hline Effect & \multicolumn{3}{c}{ Model } \\
& & M1 & M2 \\
\cline { 3 - 4 } Intercept & $\beta_{0}$ & -.05 & -.13 \\
Main effects & & & \\
Gex & $\beta_{1}$ & .08 & $.33^{* *}$ \\
NCS & $\beta_{2}$ & -.05 & $.19+$ \\
Technology & $\beta_{3}$ & $.12+$ & \\
Self & $\beta_{4}$ & & $.21^{*}$ \\
Task & $\beta_{5}$ & & $.37^{* *}$
\end{tabular}

Interaction effects

\begin{tabular}{llc} 
Gex by Tech & $\beta_{6}$ & .02 \\
NCS by Tech & $\beta_{7}$ & $.30^{* *}$ \\
Gex by Self & $\beta_{8}$ & $-.43^{* *}$ \\
Gex by Task & $\beta_{9}$ & $-.27^{* *}$ \\
NCS by Self & $\beta_{10}$ & $.26^{* *}$ \\
NCS by Task & $\beta_{11}$ & -.11 \\
\hline ** $^{*} \leq .01 ;{ }^{*} p \leq .05 ;^{+} p \leq .1 ;$ treatment contrasts \\
estimated for factors, with reference levels sports \\
(domain) and other (orientation)
\end{tabular}

$\mathrm{H} 2 \mathrm{a}$ did not find consistent support. On the one hand, self-orientation is strongly associated with need-for-cognition, but task-orientation, as the second component of mastery goals, is lowest. Furthermore, the Gex scale shows the exact opposite of what $\mathrm{H} 2 \mathrm{a}$ predicts, with otherorientation being strongest. $\mathrm{H} 2 \mathrm{~b}$ found partial support, as self-oriented goals in technology situations had the strongest association with needfor-cognition.

In summary, need-for cognition more or less showed the expected associations with achievement domain and orientation, whereas Gex did not. Instead, the Gex score was strongly associated with other-orientation in the technology domain. Seemingly, the Gex scale captures the need to show off ones skills, rather than the more intrinsic needs of improving one's ability. This theme occasionally appeared in O'Brien's interview study, for example: [...] there was one aspect of socialization that the programmers enjoyed. They knew tricks with technology that the average person did not, and so they were happy to use their 'magic powers' to show off their abilities.' (O'Brien 2007, p.80). Similarly, have power users among doctors reported to like to show off latest devices and functions' (McAlearney et al. 2004, p.1164).
So, are geeks the self-contained tinkerers and thinkers, drawing satisfaction solely from mastering intellectual challenges? Or do they engage in social comparison, thriving for being the best? Both seems to be the case. People who experience joy through intellectual challenge also show strongest orientation towards personal growth through mastery of technology. At the same time, there is a social component to it. Like for sports enthusiasts, comparison with others and the urge to being best in their fields could be a driving force of geekism.

In the present study, the theoretical perspective is that geeks have a strong need for cognition, which they are acting out in technology-related situations. Reflecting this perspective, two measures had been taken: following (Schmettow et al. 2013), NCS represented the joy of intellectual challenges. In addition, the novel Gex scale was introduced aiming more specifically at computer enthusiasm. NCS and Gex were weakly associated, and the two scores showed rather different patterns with regard to achievement goals. We conclude that discriminant validity of the Gex scale is sufficient towards NCS. But, since we could not find the expected associations with the Gex scale, further validation is required.

Future studies should also add different methods, as pure questionnaire research often has limited validity. For example, one could create a situation where participants had to master a computer system, and measure whether endurance of effort is associated with geekism scores. To further explore the role of other-oriented goals, the depicted study could introduce a manipulation of social context, for example by adding competitive elements.

For now, when attempting to assess geekism, it is advised to use both scales, as they seem to reflect different aspects of attitude towards computers.

\section{REFERENCES}

Ames, C. \& Ames, R., 1984. Goal Structures and Motivation. Elementary School Journal, 85(1), pp.38-52.

Cacioppo, J.T. et al., 1996. Dispositional differences in cognitive motivation: The life and times of individuals varying in need for cognition. Psychological Bulletin, 119(2), pp.197-253.

Cacioppo, J.T., Petty, R.E. \& Kao, C.F., 1984. The efficient assessment of need for cognition. Journal of personality assessment, 48(3), pp.306-7.

Diana, C., 2008. How I learned to stop worrying and love the hackers. interactions, 15(2), p.46. 
Dweck, C., 1986. Motivational processes affecting learning. American psychologist, 41(10), pp.1040-1048.

Elliot, A.J., Murayama, K. \& Pekrun, R., 2011. A 3 $\times 2$ achievement goal model. Journal of Educational Psychology, 103(3), pp.632-648.

Elliot, A.J. \& Thrash, T.M., 2002. Approachavoidance motivation in personality: Approach and avoidance temperaments and goals. Journal of Personality and Social Psychology, 82(5), pp.804-818.

Grant, H. \& Dweck, C.S., 2003. Clarifying achievement goals and their impact. Journal of personality and social psychology, 85(3), pp.541-53.

Hadfield, J., 2010. MCMC methods for multiresponse generalized linear mixed models: the MCMCglmm R package. Journal of Statistical Software, 33(2), pp.1-22.

Harackiewicz, J.M. et al., 2000. Short-term and long-term consequences of achievement goals: Predicting interest and performance over time. Journal of Educational Psychology, 92(2), pp.316-330.

Heijden, H. Van der, 2004. User acceptance of hedonic information systems. MIS quarterly, 28(4), pp.695-704.

Hunter, A., 2009. High-tech Rascality: Asperger's Syndrome, Hackers, Geeks, and Personality Types in the ICT Industry. New Zealand Sociology, 24(2), pp.39-61.

Lau, S., Liem, A.D. \& Nie, Y., 2008. Task- and selfrelated pathways to deep learning: the mediating role of achievement goals, classroom attentiveness, and group participation. The British journal of educational psychology, $78(\mathrm{Pt}$ 4), pp.639-62.

Marathe, S. \& Sundar, S.S., 2011. What drives customization?: Control or identity? In Proceedings of the 2011 annual conference on Human factors in computing systems - CHI '11. New York, New York, USA: ACM Press, p. 781.

McAlearney, A.S., Schweikhart, S.B. \& Medow, M. a, 2004. Doctors' experience with handheld computers in clinical practice: qualitative study. BMJ (Clinical research ed.), 328(7449), p.1162.

Nicholls, J.G., 1984. Achievement motivation: Conceptions of ability, subjective experience, task choice, and performance. Psychological Review, 91(3), pp.328-346.

O'Brien, B., 2007. Gifted geeks: The emergence and development of computer technology talent. University of Kansas.

R Development Core Team, 2011. R: A Language and Environment for Statistical Computing,
Vienna, Austria: R Foundation for Statistical Computing.

Raymond, E.S., 2008. A Brief History of Hackerdom. In C. DiBona \& S. Ockman, eds. Open Sources Voices from the Open Source Revolution. O'Reilly Media.

Schmettow, M., Noordzij, M.L. \& Mundt, M., 2013. An implicit test of UX: Individuals Differ in What They Associate with Computers. In CHI '13 Extended Abstracts on Human Factors in Computing Systems on - CHI EA '13. New York, New York, USA: ACM Press, pp. 2039 2048.

Vrugt, A. \& Oort, F.J., 2008. Metacognition, achievement goals, study strategies and academic achievement: pathways to achievement. Metacognition and Learning, 3(2), pp.123-146.

Van Yperen, N.W., 2006. A novel approach to assessing achievement goals in the context of the $2 \times 2$ framework: identifying distinct profiles of individuals with different dominant achievement goals. Personality \& social psychology bulletin, 32(11), pp.1432-45.

\section{Appendix: Gex Items}

1. I want to understand how computer parts and software work

2. Complex procedures with technical devices put me off.

3. I have sometimes modified a technical device or diverted it from its intended purpose.

4. I am motivated to optimize technical devices or configure them to my requirements.

5. I have or I would make a project or work of mine publicly available on the internet.

6. Some people would call me a computer freak.

7. I not am interested in the inner working or coding of software.

8. Challenging tasks with technical devices appeal to me.

9. I have good knowledge of computing devices

10. I invest a lot of time and effort to explore computing devices.

11. I like acquiring more knowledge of technical devices

12. I have more than once opened technical devices to see their insides.

13. Sometimes I use technical devices different to what their were intended for.

14. It puts me off when technical devices have too many settings options.

15. Usually I need help when having trouble with a technical device. 